\title{
Entre la renovación y el reciclaje de tejidos urbanos consolidados. El debate actual en Bogotá *
}

\author{
Isabel Arteaga Arredondo* \\ Clemencia Escallón Gartner ${ }^{\text {*** }}$
}

\section{Resumen}

El debate en Bogotá hoy es la relevancia puesta en la regeneración de las áreas consolidadas frente al desinterés por propiciar y regular la expansión en sus bordes. Es decir, se está apostando por transformar la ciudad existente antes que continuar el crecimiento expansivo. A pesar de la importancia dada a la ciudad existente, las intervenciones propuestas se centran exclusivamente en proyectos de renovación urbana en la línea clásica (tábula rasa). En este contexto, la idea de reciclar las estructuras existentes de barrios como estrategia urbana, no tiene aún experiencias significativas que vayan más allá del patrimonio arquitectónico en el Centro Histórico como hechos individuales. Sin embargo, podríamos afirmar que, en las áreas de asentamientos informales se ha consolidado una importante experiencia en reequipar éstos a través de lo público: equipamientos, parques, senderos peatonales, etc. Es, bajo esta idea, que podemos hablar de reciclaje de barrios, más en sus espacios libres que en sus estructuras habitacionales.

\section{Palabras clave}

Renovar; Reciclar; Regenerar; Estrategias

\section{Abstract: Between the renewal and recycling of the consolidated urban fabric. The current debate in Bogota}

The current debate in Bogotá is the regeneration of the inner city versus sprawl in in the borders. So the challenge now is to change the city, before growing in new urban spaces. Despite the recognition given to the importance of the actual city, the proposals put the efforts in the classic urban renewal where all changes will be done. The urban strategy of recycling the structures and the neighborhoods that has been developed does not have significant experiences that go beyond the architectural heritage in the historic center as individual facts. However, we could say that, at the informal urban settlements in Bogotá, it has been consolidated an important experience in re-equipment the public spaces: public buildings, parks and walk sides, that we can denominate neighborhood recycling, not in the private spaces but in the public spaces.

\section{Key words}

Renewal; Recycling; Regeneration; Strategies

\footnotetext{
Recibido: 04/06/2013; aceptado definitivamente: 12/09/2013

*Este artículo recoge algunas de las reflexiones que surgieron de investigaciones realizadas por las autoras: Arteaga (2010). Construir ciudad en territorios urbanizados. Transformaciones en la primera periferia. Tesis Doctoral. Escallón (2013). Gobernanza en procesos de regeneración urbana. Aproximaciones al caso de Bogotá. Tesis Maestría en Estudios Interdisciplinarios de Desarrollo. CIDER. Universidad de los Andes. Escallón, Arteaga, Caicedo (2010). Transformaciones en sectores urbanos en consolidación. Avances metodológicos para el análisis de intervenciones basadas en principios de renovación urbana. Arteaga, et. al., (2012). La política de renovación urbana en Bogotá. Balance sobre los planes parciales de renovación formulados entre 2005-2010.

** PhD, Arquitecta. Profesora asociada Departamento de Arquitectura Universidad de Los Andes. Bogotá (Colombia). E mail: iarteaga@uniandes.edu.co.

Arquitecta. Profesora cátedra Departamento de Arquitectura Universidad de Los Andes. Bogotá (Colombia). E mail: cescallo@uniandes.edu.co.
} 
Parafraseando a Bernardo Secchi (1984), las condiciones están cambiando de nuevo. Si durante gran parte del siglo $\mathrm{XX}$ las reflexiones sobre la ciudad estuvieron encaminadas hacia la construcción de la "nueva ciudad", es decir, la expansión urbana y el crecimiento desmedido; los actuales fenómenos y los debates recientes muestran la relevancia dada a los procesos de transformación de la ciudad consolidada, no sólo en su interior (los centros históricos o las áreas obsoletas) sino también en aquellas áreas de formación más reciente, como es el caso de la primera periferia.

Las recientes reacciones contra los años de excesos y derroche económico en la construcción de la "nueva ciudad", están derivando en una posición controlada, responsable y en cierta medida contenida sobre cómo intervenir nuestras ciudades. Un nuevo paradigma posiblemente, basado en principios no solamente de sostenibilidad, sino también de recuperación: del territorio, de las edificaciones, de las infraestructuras, de los objetos, de los materiales. Como afirma Mozas (2012, p. 9), en suma un reclamo para recobrar la dignidad y los derechos ciudadanos; reclamo que se hace evidente en acciones más "tácticas" ${ }^{1}$ y menos "estratégicas" con una actitud centrada más en la recuperación y la oportunidad que ofrece el entorno urbano consolidado.

La transformación de la ciudad construida aparece como el camino a seguir en momentos de crisis. El auge que hemos visto darse en los discursos de las intervenciones "R" (reciclar, recuperar, reformar, rehabilitar, reordenar, renovar, revitalizar.....) no es novedoso, si miramos lo que está sucediendo desde la crisis financiera desatada en 2008. La crisis cultural, económica y urbana de los años setenta derivada de la crisis energética

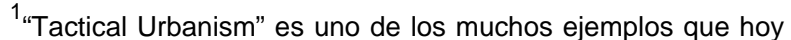
observamos en esta línea, respondiendo con efectividad e impacto a problemas urbanos concretos, y con los mínimos recursos posibles.
}

de 1973, también condujo, como lo explica Secchi (1984), a un obligado cambio en el discurso urbanístico sobre la ciudad existente. Se aceptó desde entonces que la ciudad "ya estaba hecha" y por tanto, afrontar la reconstrucción y la reutilización de lo existente, al tiempo que se evidenciaba un potencial crecimiento de las ciudades desde "adentro" que se contraponía al crecimiento exterior o por expansión, el cual había predominado como reflexión y como acción durante tres cuartas partes del siglo $X X$, especialmente durante la vigencia del proyecto moderno.

Así, recuperar lo construido no es una idea reciente. Desde la crisis de los años setenta se asume una actitud cultural y ambiental de "recuperación" de lo existente, desde la rehabilitación del patrimonio hasta la reutilización y mejora de los espacios urbanos. Un redescubrimiento de los valores de la ciudad existente irá unida desde entonces a la idea de persistencia de la historia y la memoria colectiva en el tejido físico de la ciudad.

La recesión económica de los años setenta fue propicia para privilegiar actuaciones de pequeña escala en la ciudad. La conocida expresión "SmaIls is Beautiful" (Schumacher, 1973), proveniente de la economía, tuvo impacto en la forma como desde la arquitectura se buscaba tener incidencia en la recualificación de lo existente, en una ciudad a "escala humana", construida más "desde abajo" y menos "desde arriba", donde se atendiera los problemas urbanos reales y cotidianos con efectividad, abandonando la preocupación por la eventual expansión futura y en contra de las renovaciones urbanas de tabla rasa. En suma, se rechazó el planeamiento general y se apostó por actuaciones puntuales donde la referencia obligada era el entorno en que éstas se insertaban con un principio de valoración de las preexistencias urbanas y arquitectónicas que superaron la idea de patrimonio. 


\section{Renovación vs. Regeneración}

Para Merlin y Choay (2000), la Renovación Urbana es considerada una operación que, entendida como un conjunto, conlleva la demolición y la reconstrucción de un sector consolidado, y que puede tener origen en la baja calidad de la edificación, su escasa adaptación a los cambios de actividades, la ineficiente ocupación del suelo o la escasa adaptación a los medios de movilidad. En suma, es un proceso de transformación que afecta tanto los sistemas generales como las edificaciones existentes pues se cambia el modelo de ordenación urbana preexistente.

Si bien es cierto que las operaciones de renovación urbana han sido dirigidas o lideradas en gran parte por el sector público, es igualmente cierto que son propiciadas por presiones privadas sobre un suelo bien localizado, con alto valor inmobiliario, y con un alto grado de deterioro. Por ello se le critica a este tipo de operaciones tres aspectos:

- Desde lo social, de romper lazos de barrio entre los habitantes realojados por fuera del límite de la operación y favorecer la formación de áreas residenciales o de oficinas para las clases más altas.

- Desde lo económico, de permitir beneficios importantes para los operadores privados al final del proceso, sin aprovechar las ayudas públicas utilizadas al inicio de la misma.

- Desde la morfología urbana, de oponer y desarticular barrios renovados a las condiciones del tejido urbano anterior y de su entorno.

Estas críticas han conducido a limitar este tipo de operaciones, o bien, a cambiar muchos de sus aspectos. Hoy, la renovación urbana se observa como una experiencia negativa para la ciudad y para los residentes de áreas objeto de intervención, pero, por otra parte, como experiencia positiva para los promotores inmobiliarios. En las últimas décadas, se ha dado un giro radical en este sentido al difundirse en muchos ámbitos acadé- micos la idea de Regeneración Urbana.

Para Robert \& Sykes (2000, p.17), Regeneración Urbana es "la visión y acción comprensiva e integral que se dirige hacia la resolución de problemas urbanos y que busca dar un mejoramiento permanente en las condiciones económicas, físicas, sociales y medioambientales de un área que ha sido objeto de cambio." Ello implicaría no sólo conocer mejor los procesos de deterioro, sino también, propiciar la participación de todos los actores que intervienen en un proceso de cambio, en aquello que se está intentando alcanzar y cómo lograrlo.

Para estos autores, la regeneración urbana va más allá de los objetivos de la renovación urbana, el redesarrollo urbano, la revitalización urbana ${ }^{2}$. La diferencia que establecen, por ejemplo, con la renovación urbana, es tan clara como esperanzadora: como política urbana característica de los años 70 , la renovación urbana incrementaba el rol y la inversión del sector privado con un énfasis en el reordenamiento extensivo de barrios de áreas urbanas obsoletas, buscando un mejoramiento del entorno urbano. Por contraste, la regeneración urbana surge como una política urbana propia de los años 90 que aprende las lecciones dejadas por las décadas pasadas. Se mueve hacia una manera comprehensiva de la política y de la práctica, con un enfoque integrado de los problemas y sus soluciones. La colaboración pública-privada es dominante, es decir, busca el balance entre la financiación pública, privada y voluntaria con un énfasis en el rol de la comunidad en la toma de decisiones. La regeneración urbana además introduce en el sentido más amplio la idea de sostenibilidad urbana.

Los principios de la regeneración urbana, según Roberts \& Sykes (2000, p.18-19) son:

- En relación con los recursos:

${ }^{2}$ Cfr. Tabla 2.1 "The evolution of urban regeneration", en Roberts (2000, p. 14). 
- Se basa en análisis detallado de las condiciones del área urbana.

- Adaptación simultanea del tejido físico, las estructuras sociales, la base económica y las condiciones medioambientales de un área urbana.

o Resolución de problemas de una manera balanceada, ordenada y positiva y con programas desarrollados de acuerdo con los objetivos del desarrollo sostenible.

- En relación con el proceso y gestión:

o Buscar garantizar consenso a través de la mayor participación posible y cooperación de todos los actores con un legítimo interés en la regeneración de un área urbana.

o Reconocer la importancia de dimensionar el progreso de estrategias hacia lograr objetivos específicos.

o Monitorear el cambio natural y la influencia de fuerzas internas y externas, las cuales actúan sobre áreas urbanas.

o Reconocer diferentes elementos y velocidades de los componentes de las estrategias en relación con los objetivos de la regeneración.

En definitiva, lo que interesa aquí es establecer la diferencia entre dos "maneras de hacer". Una que reordena sin tener en cuenta lo existente pues busca cambiar radicalmente las condiciones allí existentes, se desconoce la posición de la población, se negocia el suelo y para ello se le asigna un importante rol al sector privado en la financiación de estas actuaciones; versus otra, que observa y comprende la lógica de lo preexistente, reconoce a los interesados haciéndolos parte de la oportunidad de cambio, y busca de forma integral soluciones a los problemas. Respuestas diferentes a un reto común: Cómo mejorar y mantener las condiciones de las ciudades, el problema del deterioro o de la carencia, en suma, de actua- lizar y mejorar partes de ciudad que no se adaptan a las necesidades actuales. $Y$ es preciso reconocer que en las ciudades los procesos de cambio son a la vez inevitables y beneficiosos. Inevitables porque se generan nuevas demandas y oportunidades para el progreso económico y el mejoramiento de la sociedad. Benéficos porque la existencia de las fuerzas de cambio crea oportunidades para ajustar y mejorar las condiciones de las áreas urbanas (Roberts, et al. 2000, p. 11).

\section{Los asentamientos informales y la idea de oportunidad}

El interés por la primera periferia como espacio de oportunidades para repensar nuevas formas de intervención acordes con los nuevos tiempos, surge, por una parte, de su consolidación en el tiempo y la adquisición de una posición central en un territorio urbanizado; por otra parte, del crecimiento urbano más allá de los límites municipales y el reconocimiento de "diversas" periferias ${ }^{3}$.

La primera periferia está conformada en gran parte por aquellas áreas que tradicionalmente se han denominado en las ciudades latinoamericanas como "marginales" o "informales". Tanto su emplazamiento de borde o frontera, su origen por fuera del planeamiento y sus bajos estándares de calidad urbanística y habitacional, contrastan con su proceso de consolidación desde los años 60, en el caso Bogotano. Un crecimiento urbano con grandes deficiencias que se reconoce por la compra de suelo en el mercado informal y la autoconstrucción de vivienda, y que mezcla la carencia de servicios urbanos básicos, transporte, equipamientos colectivos, parques; con una ausencia de condiciones de calidad y seguridad en la vivienda. Ello da como resultado la generación de áreas urbanas incompletas pero en las cuales se reconoce de forma amplia la construcción de

\footnotetext{
${ }^{3}$ La periferia "vil" y la periferia "espléndida", comparadas así por Solá Morales, M (1998).
} 
sólidas redes sociales que generan soporte y estabilidad a sus residentes.

Por ser sectores construidos sin acatar las regulaciones de los organismos de planeación y control del espacio urbano, su desarrollo se dilata en el tiempo en la medida que sus habitantes cuenten con los recursos para ir adecuando los espacios que habitan, lo que implica el esfuerzo de toda una vida para muchas de estas familias (Saldarriaga, 2001). Con respecto a la estructura urbana y de servicios, su desarrollo es producto de la movilización de la comunidad para que sus demandas en cuanto a servicios básicos, espacio público, legalización de la propiedad ${ }^{4}$, sean atendidas por el Estado ${ }^{5}$. Las acciones que se han emprendido han sido prácticamente de mejoramiento del espacio urbano a partir de lo que ha quedado sin ocupar (urbanización de calles, espacio público y equipamientos), mejorando las condiciones de calidad de vida de las personas que allí habitan. Es, en esta línea, que se podría hablar de reciclaje urbano en barrios marginales.

En estas áreas, las intervenciones en las ciudades latinoamericanas se han orientado en gran medida desde intervenciones físicas para superar carencias de servicios públicos, y en algunas oportunidades -como el programa Favela Barrio en Río de Janeiro y el programa de Mejoramiento Integral de Barrios en Bogotá- se han formulado propuestas más completas en relación con sus dimensiones y componentes de intervención. A las experiencias conjuntas de intervenciones de espacio público, infraestructura de servicios y equipamientos, se ha sumado propuestas que

\footnotetext{
${ }^{4}$ La legalización hace las veces de incorporación y reconocimiento de la condición de suelo urbano.

${ }^{5}$ En Bogotá, cuando una comunidad, sin importar su modalidad de conformación, logra organizar una Junta de Acción Comunal, se inicia un proceso de legalización de la ocupación ante la Secretaría Distrital de Planeación, y si quedan espacios disponibles, se tramita el permiso para construir servicios comunales. La prestación de servicios públicos legales se gestiona a partir de este momento, una vez se legaliza la ocupación.
}

permiten la participación de la ciudadanía organizada en la reflexión sobre el ordenamiento territorial y las decisiones sobre norma urbana, que a pesar de ser más estructuradas en términos de la escala urbana y los posibles impactos en la calidad del entorno, no han dado los resultados que se esperaban, si además se compara con las experiencias de intervención de menor escala, de influencia vecinal, surgidas del conocimiento de las necesidades reales y respuestas rápidas y efectivas a éstas.

\section{Renovar, una lógica inmobiliaria. La estrategia actual de la ciudad en el centro}

Desde el inicio de los años $60^{6}$, se ha demostrado el interés de las administraciones públicas por conformar una estructura urbana compacta, que pudiese dar orden a una ciudad que tiene como principal lógica la expansión desmedida e incontrolada frente al aumento del abandono de las áreas centrales y su consecuente deterioro. Procesos como la relocalización de actividades y especialización de áreas, la sustitución de inmuebles obsoletos, y la renovación urbana con cambio de ordenación del espacio urbano, han sido las estrategias más comunes.

Desde entonces en Bogotá se ha apostado prácticamente por la renovación urbana frente a otras actitudes de menor impacto para transformar la ciudad consolidada. De acuerdo con Salazar y Cortés (1992), durante la segunda mitad del siglo $\mathrm{XX}^{7}$ han coexistido dos formas de renovación urbana, sin que ello haya conformado un bagaje teórico o práctico sobre cómo aprender del deterioro, la obsolescencia y su actualización y mejoramiento:

- Como operación para modernizar la

\footnotetext{
${ }_{7}^{6}$ Alcaldía Mayor de Bogotá (1964).

${ }^{7}$ Período en el cual se reconoce en Bogotá su ordenamiento como resultado de un ejercicio de planeamiento.
} 
estructura urbana. Se entiende bajo un espíritu reformador e higienista que busca el saneamiento del espacio urbano y el mejoramiento de la vivienda, a través de un nuevo ordenamiento. Se caracteriza por los cambios radicales de uso o densidad para satisfacer nuevas necesidades. Generalmente se llevó a cabo y se sigue haciendo en las áreas centrales. (Ver Figuras. 1, 2, 3).

- Como instrumento normativo para incidir sobre el aprovechamiento de la renta de predios de localización central y oportunidad inmobiliaria. Si bien la norma es definida por el sector público, con ésta se apoya la iniciativa pri vada sin que surja de una necesidad de cambio por deterioro u obsolescencia, pero si implica densificación y uso intensivo del suelo. (Ver Figura 4).

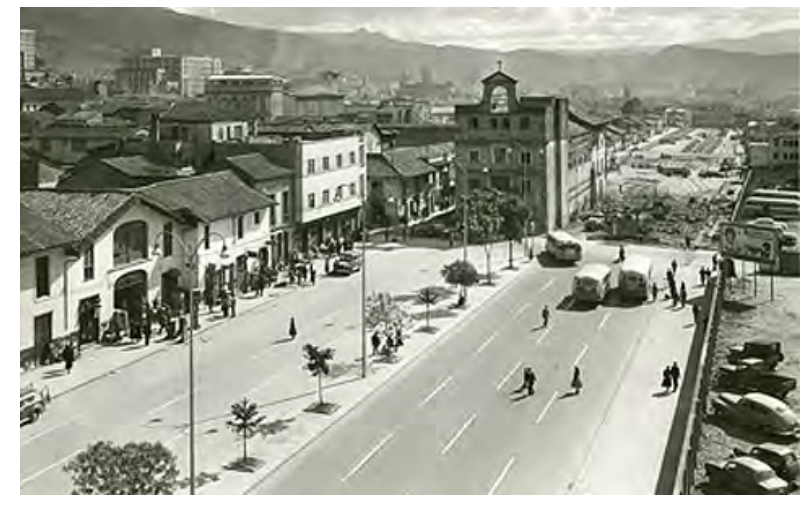

Figura 1. Apertura de la Carrera 10 en el centro de Bogotá hacia los años 50. Fotografía de Paul Beer. Fuente: Archivo de Bogotá.

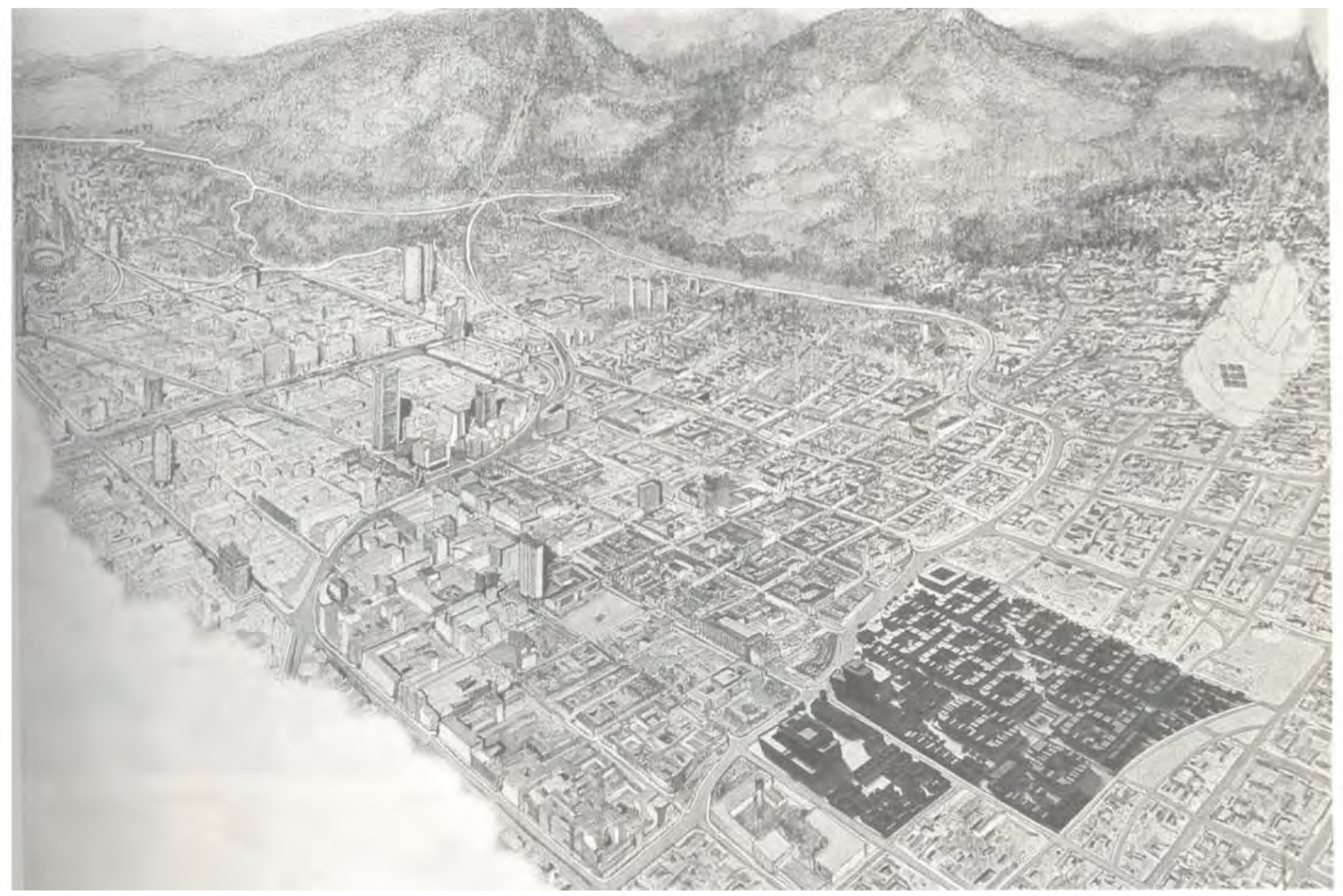

Figura 2. Proyecto de Renovación Urbana en el barrio Santa Bárbara - Nueva Santafé (1985). Fuente: Revista Escala. 


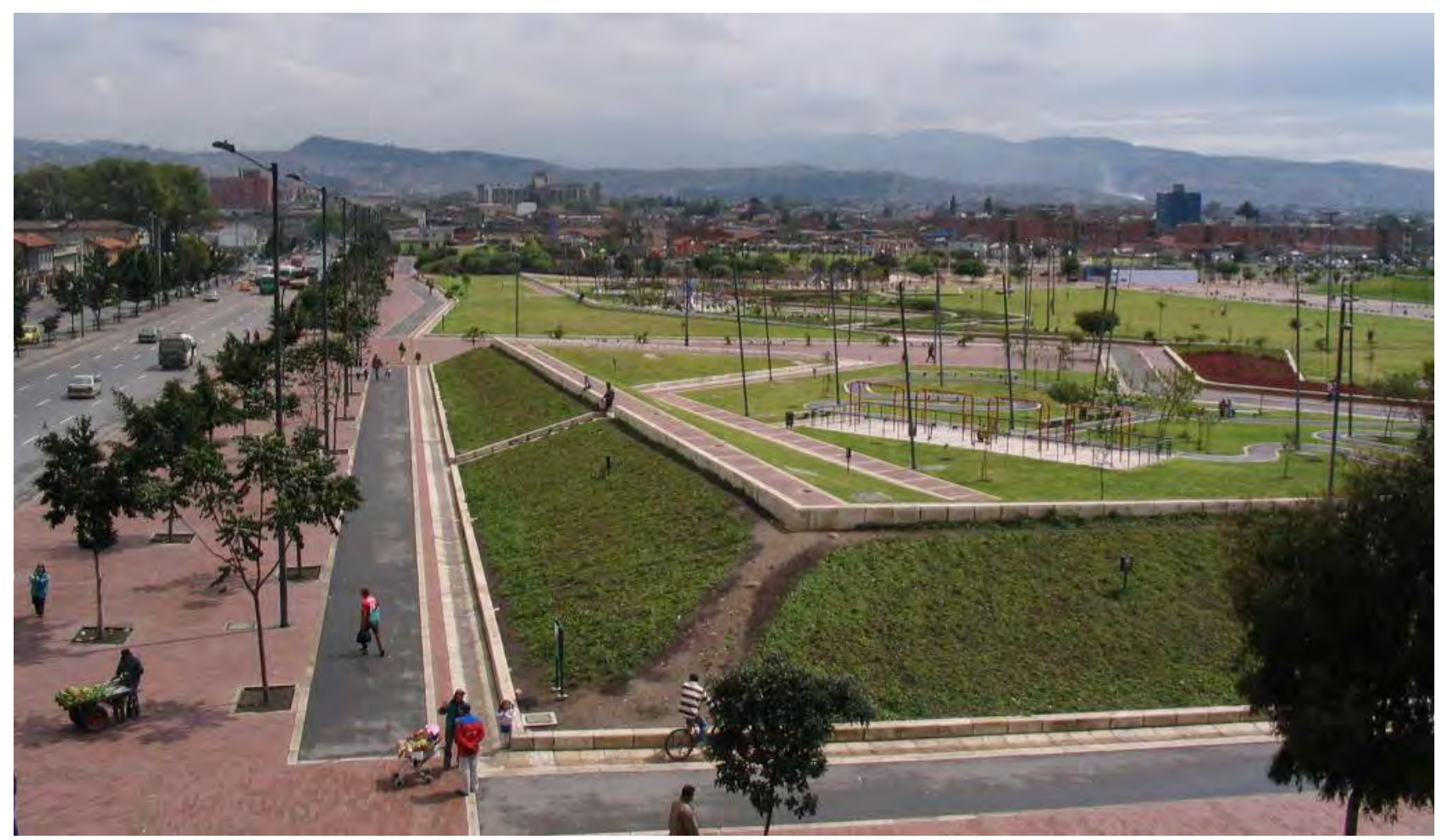

Figura 3. Proyecto de Renovación Urbana en San Victorino, Bogotá (2000). Fuente: Isabel Arteaga (2009).

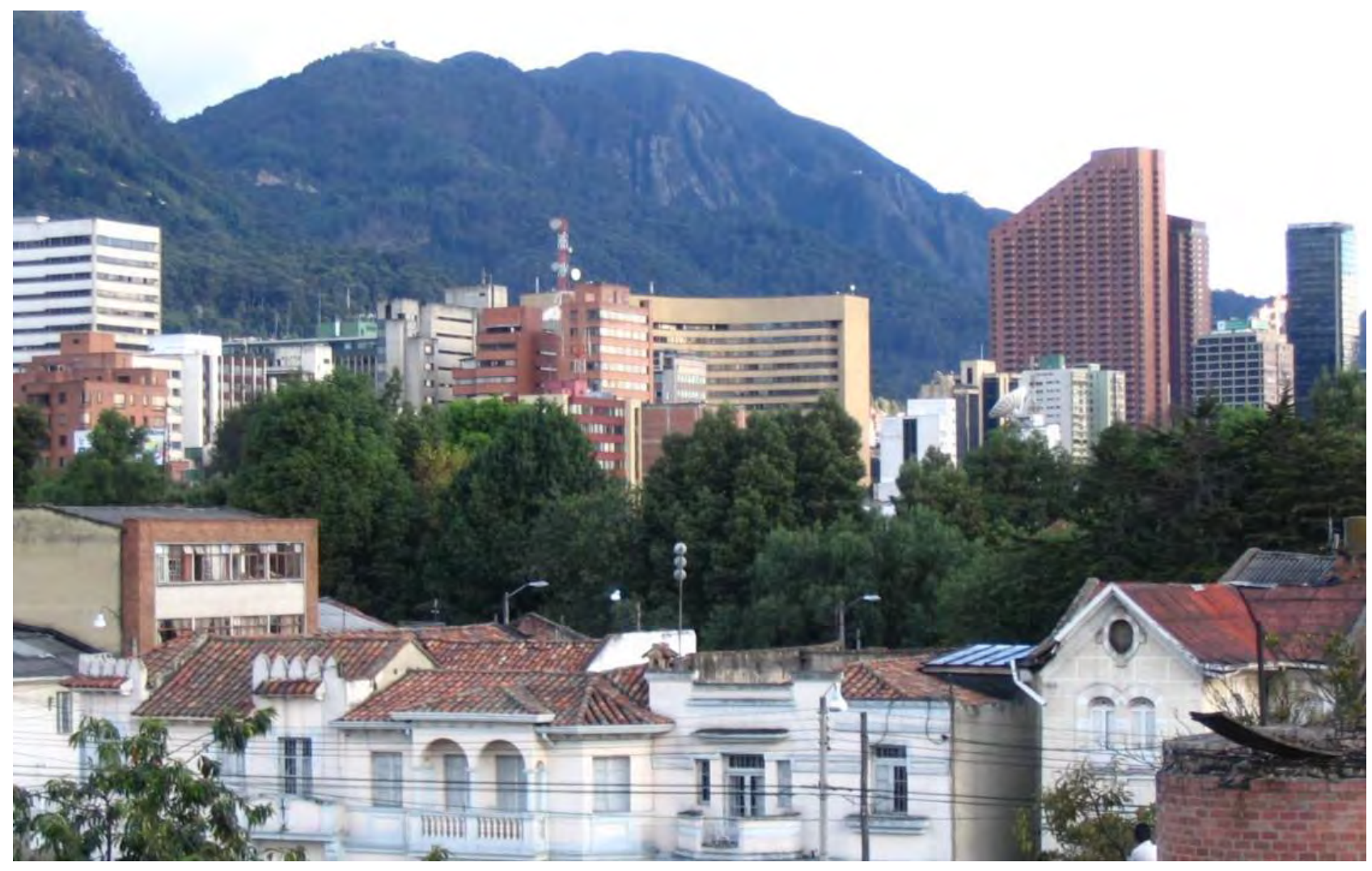

Figura 4. Barrios centrales de Bogotá transformados a partir de la normativa predio a predio. Teusaquillo y San Martín. Fuente: Isabel Arteaga (2008). 


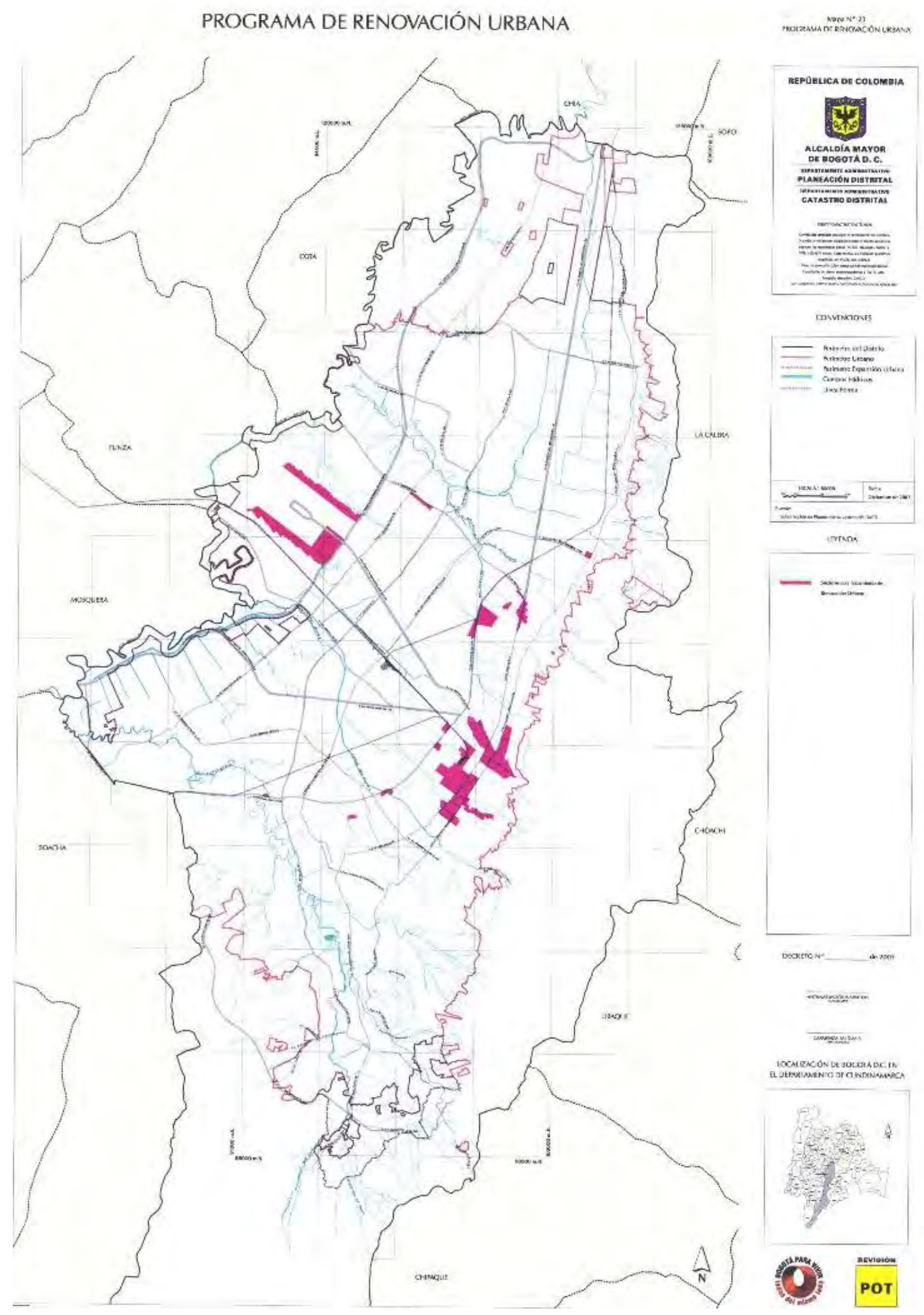

Figura 5. Programa de Renovación Urbana en Bogotá. Plano Oficial del P.O.T 2004. Fuente: Decreto 190 de 2004. 
Desde la formulación del Plan de Ordenamiento Territorial de Bogotá (P.O.T) en el año $2000^{8}$, la renovación urbana ha tomado un rol relevante como estrategia de actuación. En este plan se define como una política de reordenamiento de la estructura urbana, para zonas con localización estratégica (central), y que han perdido funciones y calidad habitacional, y presentan deterioro en actividades y degradación del espacio libre y el espacio edificado. De hecho, se concibe como una política y un programa. Como política, tiene como función lograr el modelo de ciudad compactada buscado para frenar la expansión de baja densidad y al tiempo garantizar la sostenibilidad y preservación del territorio. Como programa se concreta en dos vías: a través de Planes Parcia$\operatorname{les}^{9}$ y a través de un tratamiento normativo (ver Figura 5).

Como tratamiento normativo, el plan señala áreas de la ciudad construida hasta los años 60 con especial énfasis en la calificación del suelo del Centro Tradicional, precisando dos formas de actuación: a) por redesarrollo, es decir, donde se permite un reordenamiento basado en la sustitución total o parcial de los sistemas generales y del

${ }^{8}$ Con la Ley 388 de Ordenamiento Territorial y la recuperación del planeamiento físico en Colombia, la formulación de los primeros Planes de Ordenamiento Territorial en las ciudades es el detonante de una nueva forma de afrontar el ordenamiento urbano frente a la situación precedente en las décadas de los años 80 y 90 y el predominio del planeamiento económico. El P.O.T de Bogotá se formula por primera vez en el año 2000 y tuvo una revisión en el año 2003, la cual está vigente hasta hoy. En este momento la ciudad se encuentra discutiendo si se aprueba una modificación excepcional del plan del año 2003.

${ }^{9}$ De acuerdo con el Decreto 2181 de 2006. Art. 2 , se entiende como Plan parcial "El instrumento mediante el cual se desarroIlan y complementan las disposiciones de los planes de ordenamiento territorial, para áreas determinadas del suelo urbano y para las áreas incluidas en el suelo de expansión urbana, además de las que deban desarrollarse mediante unidades de actuación urbanística, macroproyectos u otras operaciones urbanas especiales, de acuerdo con las autorizaciones emanadas de las normas urbanísticas generales, en los términos previstos en la Ley 388 de 1997. Mediante el plan parcial se establece el aprovechamiento de los espacios privados, con la asignación de sus usos específicos, intensidades de uso y edificabilidad, así como las obligaciones de cesión y construcción y dotación de equipamientos, espacios y servicios públicos, que permitirán la ejecución asociada de los proyectos específicos de urbanización y construcción de los terrenos incluidos en su ámbito de planificación." espacio edificado, insertando nuevos usos y permitiendo un aprovechamiento edificatorio más alto que el existente y exigiendo nuevo espacio público; y b) por reactivación, es decir, donde se requiere mejorar parcialmente el espacio público y se permite una sustitución parcial del espacio edificado. Pero de cualquier forma, permite una intensificación en la utilización del suelo y de la edificabilidad.

Los planes parciales de renovación son, en síntesis, un área delimitada al interior de un sector cuyo tratamiento normativo es de Renovación por Redesarrollo, que puede ser objeto de un nuevo ordenamiento llevado a cabo por un proceso de gestión en cabeza de la administración pública, un operador privado o bien, una alianza de ambos. Desde el año 2005 se han formulado y presentado ante las autoridades distritales alrededor de treinta planes de este tipo, localizados en áreas centrales de la ciudad, y que van desde las 2,9 hectáreas hasta 36 hectáreas. Las dificultades que se han presentado para la aprobación y puesta en marcha de estos planes se evidencia en que, hasta hoy, se han aprobado solamente dos: Uno de iniciativa privada ubicado en un área de centralidad y vinculado a un equipamiento cultura de gran impacto (Proscenio) y otro de iniciativa pública vinculado a un proyecto de movilidad localizado en una zona central deteriorada (Estación Central del Sistema de transporte masivo).

Un análisis reciente de 8 de los planes parciales formulados $^{10}$ (ver Figura 6) concluye que éstos se caracterizan por intervenir en áreas consolidadas hacia los años 50 y 60, con una alta fragmentación parcelaria y una localización estratégica frente a los sistemas de transporte masivo, proponiendo unos altos índices de construcción (entre 5

\footnotetext{
${ }^{10}$ Arteaga et al. (2012). La política de renovación urbana en Bogotá. Balance sobre los planes parciales de renovación formulados entre 2005-2010.
} 
y 7 cuando en Bogotá el promedio es de 2,5) y por tanto aumentando significativamente la densidad, en contraste con escasas cesiones para espacio público y prácticamente inexistentes para equipamientos colectivos. Finalmente, una escasa participación en las decisiones de estos planes por parte de los residentes afectados, si no es a través de la compra de su predio por parte del operador.

En definitiva, a pesar de los esfuerzos no se ha logrado generar una dinámica mínimamente aceptable en relación con los procesos de renovación. Los interesados desde el sector privado cuestionan la poca claridad normativa, mientras que desde el sector público se reclama mayor correspondencia de las propuestas presentadas por los privados con el modelo de ciudad, y los residentes visualizan con preocupación el enfoque netamente especulativo de las propuestas y reclaman proyectos más incluyentes que permitan a los residentes mantenerse en los sectores sujetos a renovación. Las preguntas por el comportamiento de este tipo de procesos se hacen para tratar de explicar, desde la trayectoria y los actores, los factores del estancamiento en la última década (Escallón, 2013).

Desde un punto de vista conceptual y pragmático, el actual Plan de Desarrollo Distrital (2012-2016) Bogotá Humana ${ }^{11}$ da un giro en el sentido mismo de la acción de renovar, al insertar el término "revitalizar". Una de sus estrategias es "Orientar los procesos de renovación urbana hacia proyectos incluyentes e integrales, que tengan como prioridad proteger la permanencia de los propieta-

\footnotetext{
${ }^{11}$ Plan de Desarrollo Económico, Social, Ambiental y de Obras Públicas para Bogotá D.C: 2012-2016 "Bogotá Humana". Acuerdo 489 de 2012 (12 de junio de 2012). Un Plan de Desarrollo es un programa de gobierno de un Alcalde a desarrollar durante su mandato (se apoya en la Ley 152/94), para llevar a cabo políticas sociales y económicas de los municipios; mientras un Plan de Ordenamiento Territorial determina acciones físicas sobre el territorio a corto, mediano y largo plazo, pues cobija como mínimo tres administraciones municipales (Ley $388 / 97$ de Ordenamiento Territorial). A pesar de las diferencias, deben estar articulados.
}

rios y habitantes originales o su vinculación voluntaria a proyectos asociativos, con una distribución equitativa de las cargas y los beneficios. Por medio de la coordinación de las inversiones públicas y privadas, y los instrumentos normativos y de planeación y gestión se apoyará una movilización más ágil del suelo para los proyectos de revitalización en el centro ampliado, con la inclusión de vivienda de interés prioritario y mayor calidad de vida de sus habitantes. Los proyectos con usos rentables tendrán que ser autofinanciados y cubrir las inversiones requeridas para la densificación y se estimularán aquellos que incluyan vivienda de interés prioritario" (2012: 5). Es decir, busca cambiar uno de los aspectos más negativos de las experiencias de renovación urbana en Bogotá como ha sido el desplazamiento de la población original de áreas objeto de este tipo de intervenciones $^{12}$.

De acuerdo con este Plan de Desarrollo, Revitalización consiste en "intervenir zonas deterioradas o con precarias condiciones urbanísticas, ambientales, con el propósito de actualizar las infraestructuras de servicios públicos, aprovechar la oferta de transporte público, aumentar la oferta de espacio público y equipamientos, recuperar su significado como bien colectivo y patrimonial, potenciar su dinámica socioeconómica, aumentar el verde urbano y mejorar las oportunidades de la ciudadanía en el acceso a un hábitat humano" (2012: 27).

\footnotetext{
${ }^{12}$ Entre las experiencias de renovación urbana más criticadas desde los años 80 hasta hoy, se encuentran la Nueva Santafé (1985) proyecto del Banco Central Hipotecario en el antiguo barrio de Santa Bárbara, y la Manzana 5 del barrio Germania (2005), ambos en el Centro Tradicional de Bogotá. Tienen como aspectos comunes el desplazamiento de la población original y el reemplazo de ésta por otros grupos sociales de mayor poder adquisitivo, la compra de predios para su englobe y el aumento de los precios de la propiedad, y la permanencia hoy de áreas vacías que han continuado con el proceso de deterioro de su entorno próximo.
} 


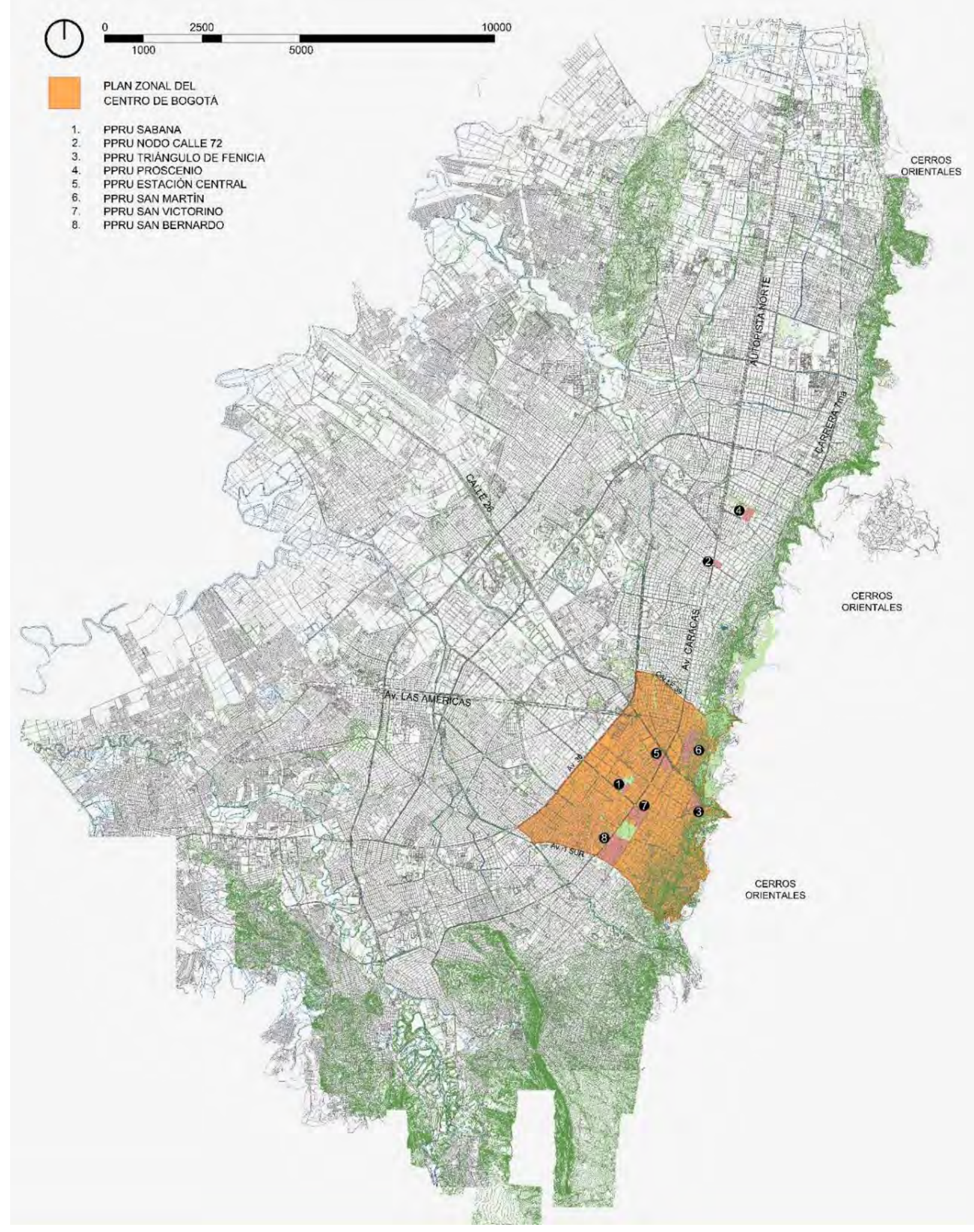

Figura 6. Localización de ocho de los planes parciales de renovación urbana en Bogotá. Fuente: Elaboración propia a partir de información de la Secretaría Distrital de Planeación (2012).

Se propone entonces un programa preciso que, en concordancia con la definición anterior, busca generar nueva oferta de vivienda y promover la mixtura de actividades y de grupos sociales, en un área que supera ampliamente el Centro Tradicional e incluye zonas industriales que han perdi- 
do su vigencia, y barrios construidos durante la primera mitad del siglo XX. Esta zona se ha denominado Centro Ampliado y cubre aproximadamente 9.545,28 ha. (Figura 7).

La estrategia que se propone para revitalizar el Centro Ampliado es desarrollar proyectos urbanos de iniciativa pública y/o en alianzas con el sector privado, apostando por la compactación y densificación. La actuación pública se centraría en la producción de vivienda social y la mejora de las infraestructuras de movilidad y servicios públicos, y vigilaría que tanto el patrimonio como los residentes originales se protegieran, así como también, la definición de reglas de juego claras y la simplificación de normas y procedimientos para la puesta en marcha de los proyectos liderados por iniciativa privada.

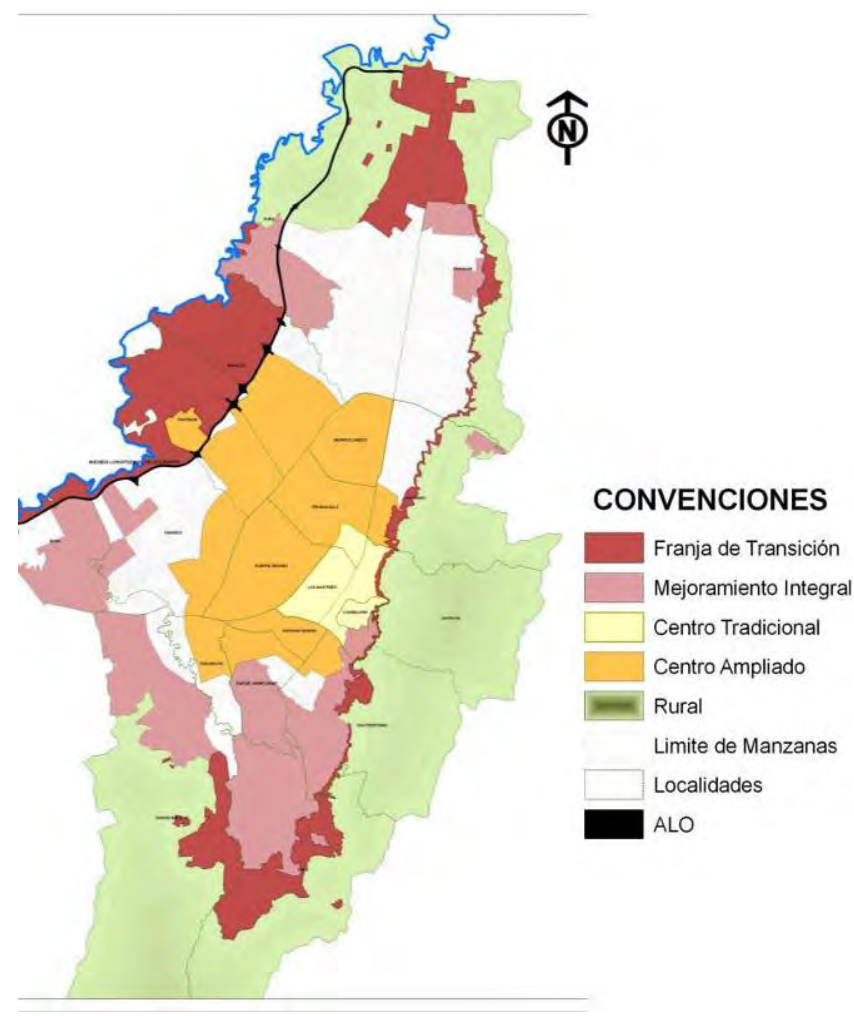

Figura 7. Centro Ampliado de Bogotá. Fuente: Plan de desarrollo económico, social, ambiental y de obras públicas para Bogotá D.C., 2012-2016 "Bogotá Humana".

A pesar del cambio hacia una nueva posición sobre el cómo debe intervenirse la ciudad consolidada, es preciso señalar que los proyectos re- cientemente aprobados van más en la línea anterior de renovación urbana a manera de tabla rasa, donde predomina una nueva ordenación urbana que no reconoce ningún tipo de valor en las preexistencias físicas, sociales y económicas, y que a su vez, tanto si es actuación pública como privada, busca el aprovechamiento inmobiliario al máximo. Nada más parecido a las intervenciones de los años 60 y 70 como las que hoy vemos propuestas en Bogotá, tales como Proscenio y Estación Central.

El caso de Proscenio es muy significativo para entender los problemas de la actual estrategia de renovación / revitalización. El proceso se inició hace diez años, para una zona de gran valorización en el norte de la ciudad (Figura 8) para la construcción de la sede de una compañía musical de alto reconocimiento en la ciudad y se propuso la construcción de un gran teatro y otros servicios comerciales y de oficinas. Solo ocho años después logró la aprobación del Plan Parcial pues se presentaron innumerables dificultades por la delimitación del área de intervención y la compra de suelo que generaron conflictos entre los promotores, y los vecinos y propietarios. (Figura 9).

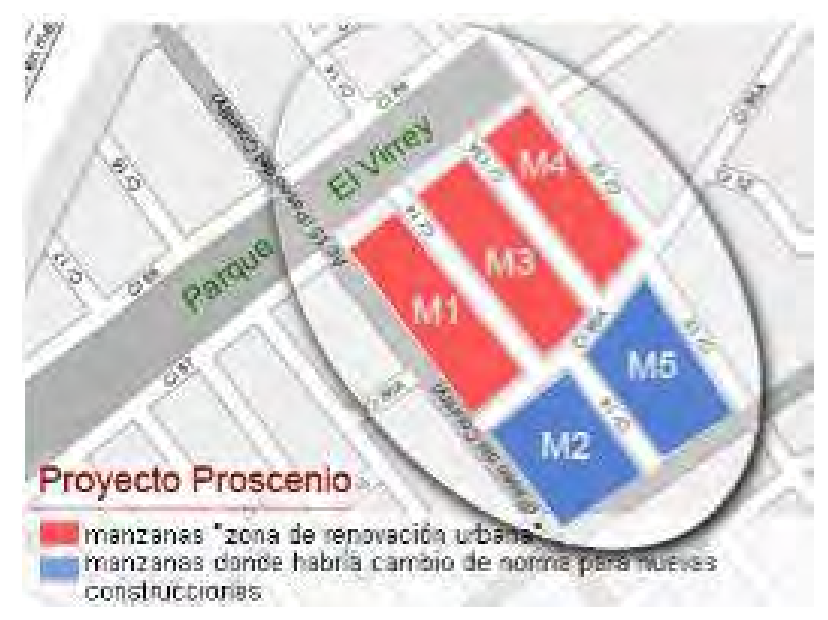

Figura 8. Plan Parcial Proscenio. Manzanas de intervención. Fuente: Empresa de Renovación. <http://www.eru.gov.co/>. (Consultado el 30 de octubre de 2013). 


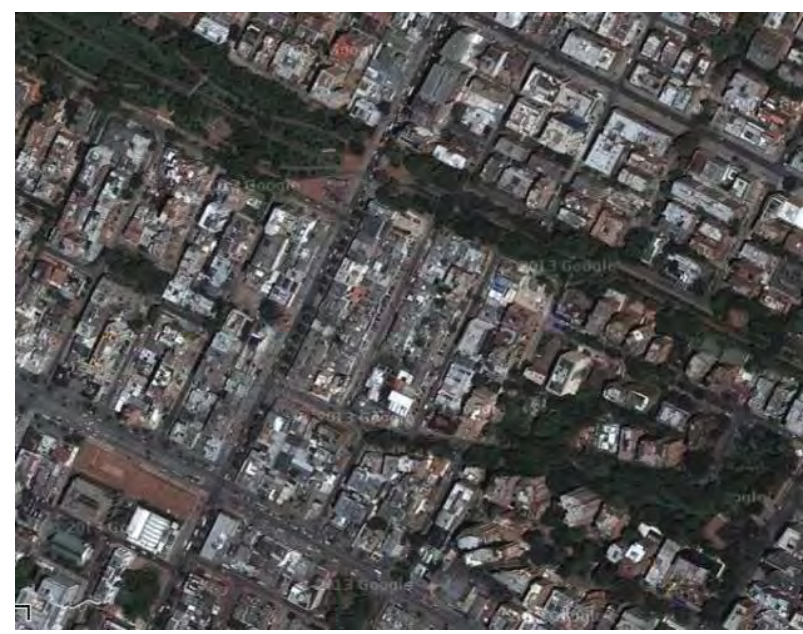

Figura 9. Zona urbana de aplicación del Plan parcial Proscenio. Fuente: DigitalGlobe (26/3/2013, captura mediante Google Earth) (Consultado el 31/10/2013).

Si bien desde la norma, el Plan Parcial pretende conciliar los intereses de los propietarios del suelo con la iniciativa de los promotores privados, la realidad es otra. Permanecen las lógicas de actuación urbana anterior donde un inversionista, siguiendo pautas únicamente de negocio inmobiliario, compra uno o más lotes y después, sin necesidad de aplicar ningún proceso de planeación, propone un gran proyecto de edificación ${ }^{13}$.

Es entonces un instrumento del planeamiento bien intencionado en términos de la ciudad, pero que aún no encuentra un camino en el proceso de gestión. En el caso de Proscenio los propietarios de inmuebles se resisten a entrar en un negocio que no comprenden, no se sienten convocados ni motivados a participar en un proyecto cultural donde no es claro su beneficio, y las entidades públicas no proceden a la aplicación de procesos de expropiación como lo dice la legislación, porque tampoco hay claridad sobre la actuación en beneficio de un tercero (Figura 10).

Los problemas anteriores son evidentes efectos de una transformación urbana de tábula rasa. No

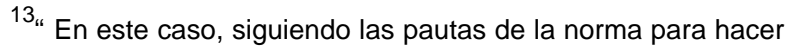
factible el plan parcial, un solo inversionista compró el 51\% del suelo de lo que se propuso como primera unidad de actuación (Escallón, 2013).
}

se reconocen las dinámicas del territorio, se aplican las estrategias equivocadas y los conflictos bloquean los procesos. Diez años de trámite, que aún no logra ni siquiera una licencia de urbanismo para la primera manzana, así lo demuestran. Sin embargo en Bogotá parece que las experiencias negativas no generan aprendizajes. En el recientemente aprobado plan parcial de renovación de iniciativa pública denominado Estación Central, las características del mismo, muy similares a las de Proscenio, generan muchas incertidumbres. Si bien es un área central altamente deteriorada, se plantean diez hectáreas de transformación urbana que modifica de manera importante el perfil urbano y la dinámica de relaciones y actividades de la zona (Figura 11).

Las expectativas en relación con el tiempo de gestión anunciadas por la Empresa de Renovación Urbana de la ciudad -diez años para la primera de tres etapas- parecen seguir la misma dinámica mencionada en relación con Proscenio. No se evidencian cambios en la gestión, porque parecería que no hay cambios en la estrategia de aproximación, desperdiciando la oportunidad de ser el primer escenario de revitalización en el que está curiosamente empeñada la misma administración distrital.

En definitiva, la política de renovación urbana en Bogotá ha sido objeto de constante debate sin lograr consensos al respecto. No existe una posición crítica sobre los efectos que hasta el momento ha tenido este tipo de actuaciones radicales, el marco normativo necesario para orientar este tipo de intervención no es preciso, las entidades públicas encargadas de liderar estos procesos no logran avanzar en planeamiento y gestión, la ciudadanía que se ha visto más afectada que involucrada en estos procesos no ha alcanzado una participación efectiva hasta el momento en la toma de decisiones. En conclusión, son pocos los avances en este tema. 


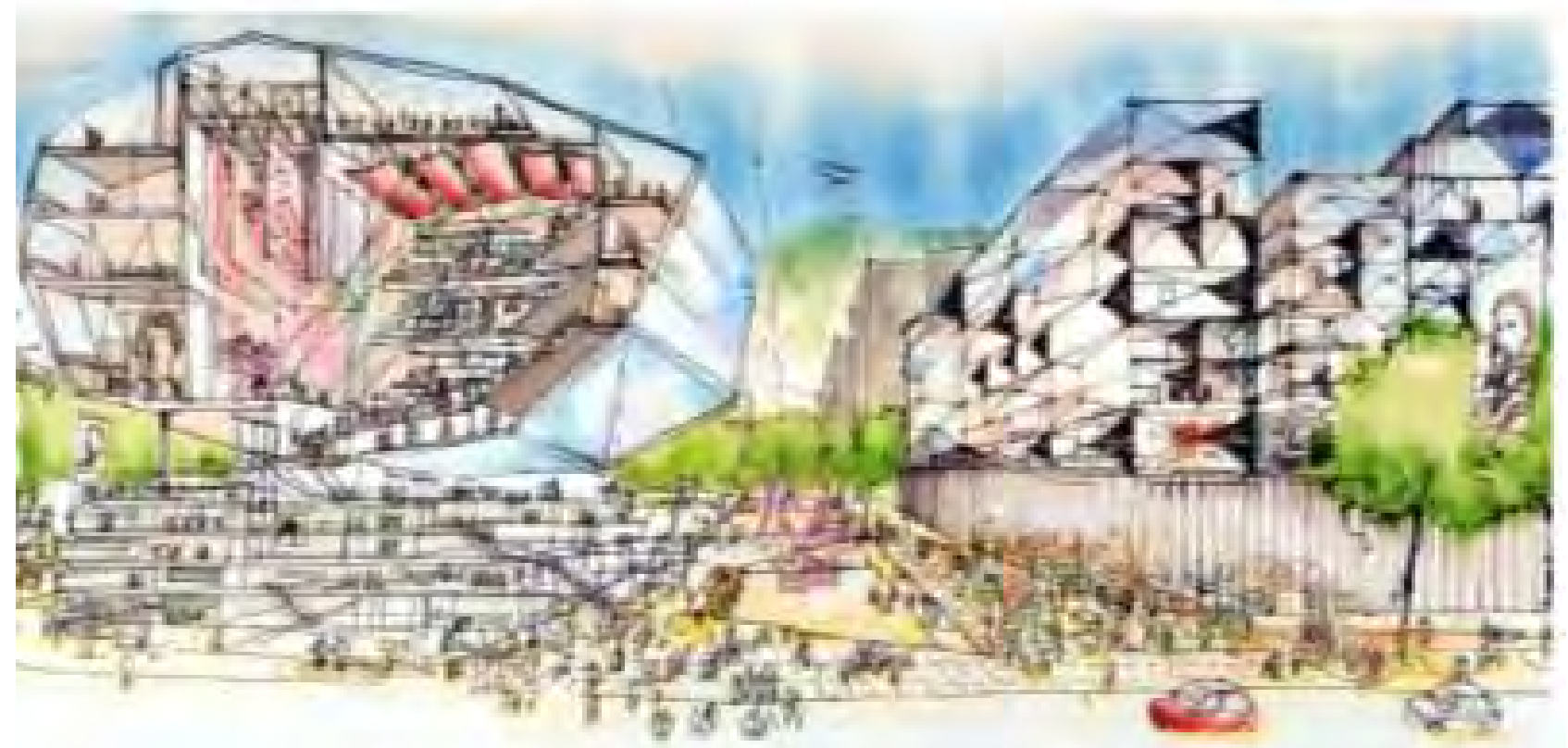

Figura 10. Centro cultural y espacio público. Proscenio, Manzana 1, 2012. Fuente: Plan parcial Proscenio. Unidad de Actuación 1, Julio 2012.

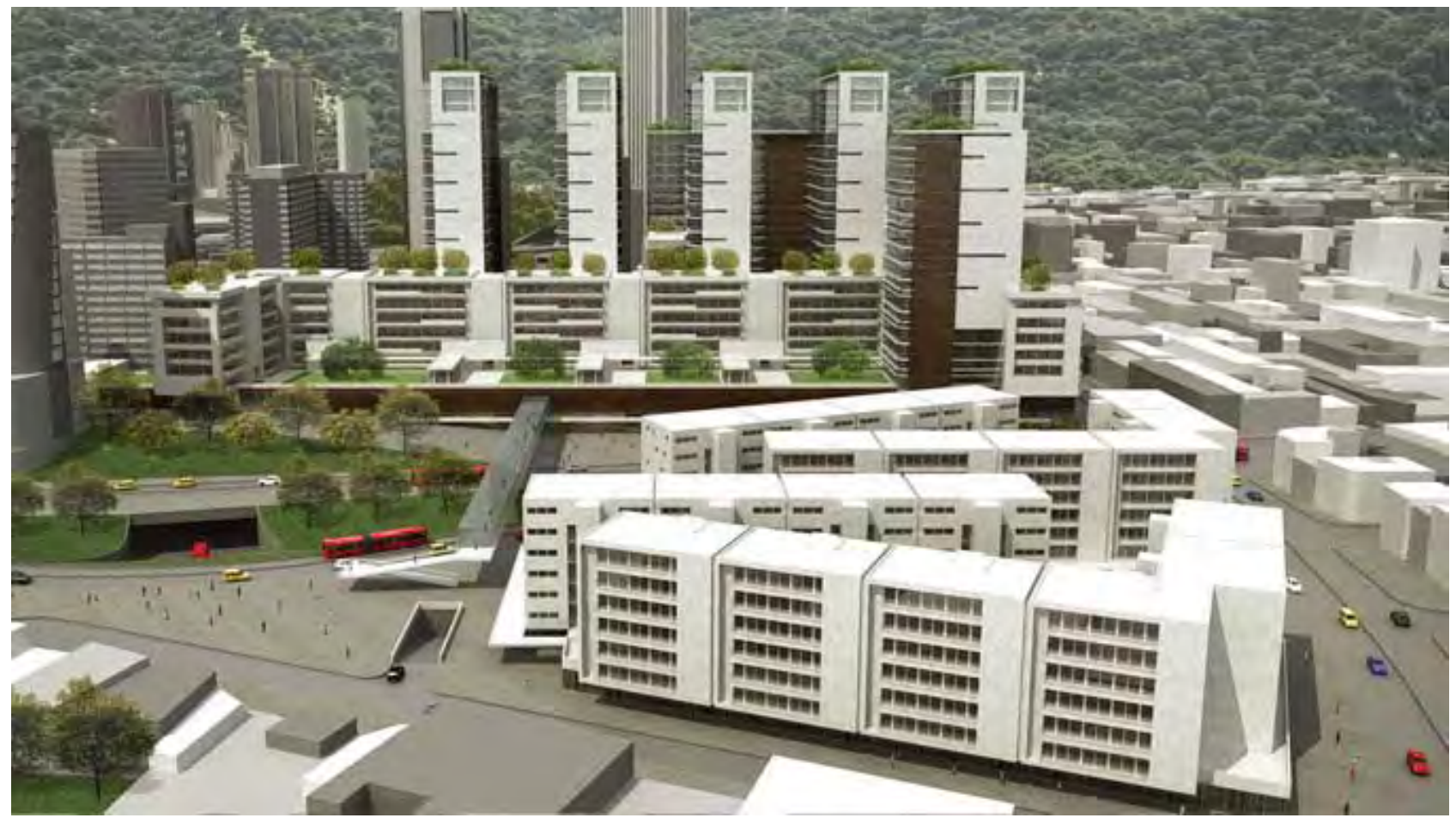

Figura 11. Estación Central. Fuente: Empresa de Renovación urbana. <http://www.eru.gov.co/>. (Consultado el 30 de octubre de 2013). 


\section{Reciclaje, una lógica desde lo público. Aproximaciones a entornos barriales}

Como se mencionó anteriormente, la dinámica urbana de Bogotá, al igual que muchas ciudades en América Latina, se caracteriza por la presencia importante de desarrollos denominados informales a los cuales durante décadas se han aplicado diferentes estrategias de reconocimiento y actuación desde las entidades públicas. El más generalizado en este caso, es el llamado proceso de legalización de barrios, que permite la incorporación a la dinámica urbana de los asentamientos en consolidación, para permitir la dotación de infraestructura legal. Posteriormente y en complemento a esta condición, en la última década se han desarrollado propuestas más integrales de actuación, donde además de los aspectos físicos de espacio público y equipamientos se han incorporado componentes sociales y de participación política.

La escala territorial de esta condición urbana para el 2010 en Bogotá, según la Secretaría Distrital de Planeación en los documentos de diagnóstico, correspondía al $25 \%$ del suelo urbano en el cual se asentaban aproximadamente 2.5 millones de personas (ver Figura 12). Este panorama evidencia la pertinencia de la reflexión de expertos como Enrique Ortiz ${ }^{14}$, quien menciona que "la mejora de barrios de autodesarrollo es una asignatura pendiente de la humanidad" o como lo resalta también Salas (2005) en el mismo documento, "es una acción impostergable de justicia social y derecho de todos los habitantes a ciudades y a condiciones de vida dignas y sustentables".

\footnotetext{
${ }^{14}$ Prólogo en Salas, J (2005).
}

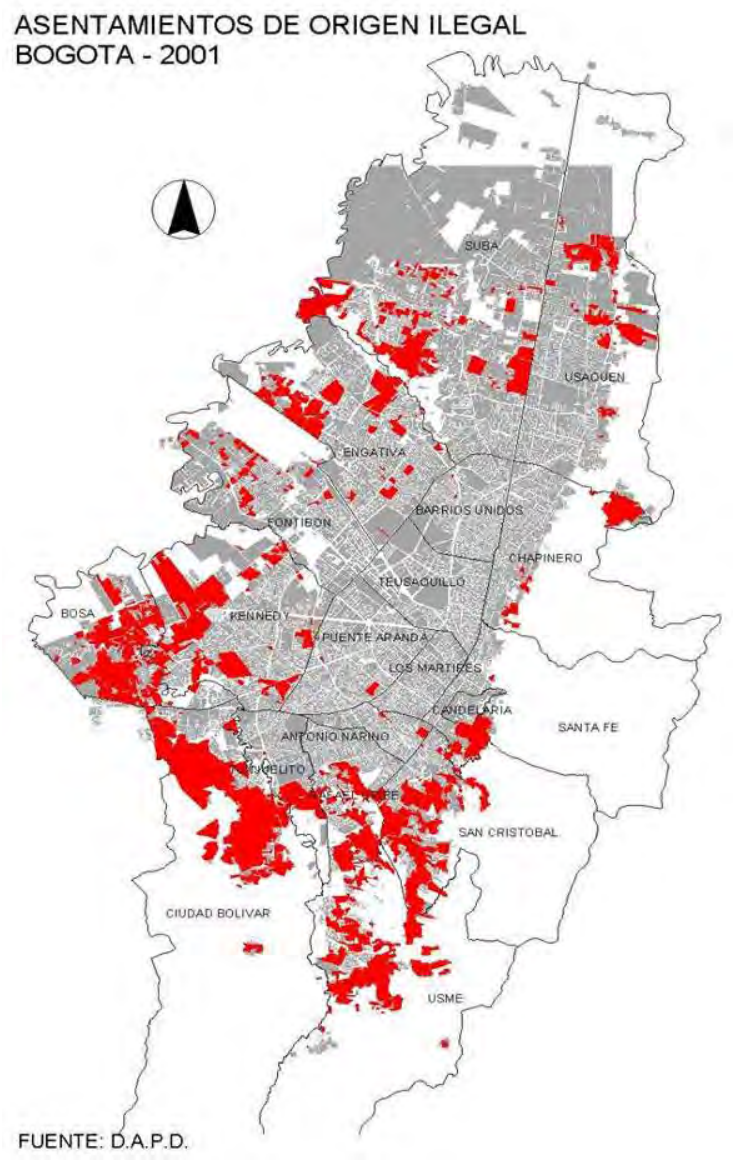

Figura 12. Plano de Asentamientos Informales en Bogotá. Fuente: DAPD. Documento técnico de Soporte P.O.T. 2000.

En este sentido es interesante reconocer el interés que ha tenido la administración distrital en Bogotá, por enfocar acciones y recursos en procura de una ciudad más equitativa. Durante varias décadas se han configurado experiencias significativas que han avanzado en el propósito de integrar acciones tanto públicas institucionales como cívicas, para definir espacios de concurrencia para la construcción de equipamientos y espacio público de escala zonal y vecinal. Una de las experiencias más significativas y que generó un impacto importante en el mejoramiento de estos entornos, lo constituyó el proyecto de Obras con Saldo Pedagógico-O.S.P. $P^{15}$, que propuso sacar lo

\footnotetext{
${ }^{15}$ El programa se inició en 1996 en la administración MockusBromberg (1994-1997) y se mantuvo con la misma metodología durante las dos siguientes administraciones hasta el año 2003, cuando se modificó bajo el nombre de Obras con Participación Ciudadana (2008-2011).
} 
pedagógico del aula, asumiendo las acciones de la vida pública y social para enriquecer la vida comunitaria en el barrio. Como se expresa en los documento de formulación del proyecto se trataba de construir una pedagogía colectiva para el enriquecimiento de la vida comunitaria, ligando el proceso- construir sociedad, con el producto obra civil.

El barrio y el espacio público, como elementos constitutivos de lo urbano, permitieron conjugar intereses y necesidades, relaciones de conflicto con escenarios de cooperación y solidaridad, donde además se posicionaron la participación ciudadana y la organización comunitaria como asuntos públicos relevantes en la reflexión política sobre la ciudad y su futuro. Un aspecto fundamental fue el cambio de actitud en la gestión urbana al involucrar a los ciudadanos como actores del desarrollo; O.S.P permitió la articulación de actores comunitarios e institucionales donde se aplicaron metodologías específicas para los procesos de información y consulta, para generar espacios de concertación y decisión, ejecución y fiscalización de recursos. En la formulación de los objetivos se mencionaba: "es hora de dejar de luchar por sobrevivir y aprender a vivir" ${ }^{16}$.

La dinámica del programa tuvo un crecimiento vertiginoso. Los informes de la coordinación del programa en el año 2.001 mostraron resultados muy significativos: 3.338 organizaciones sociales de base vinculadas a casi 700 obras entre parques, salones comunales, vías peatonales, en 19 de las 20 localidades de la ciudad (ver Figuras 13 y 14).

Los aprendizajes de este proyecto se incorporaron en dos escenarios de alta significación: el plan de desarrollo 1998-2000, en el programa de Desmarginalización, y en las decisiones del Plan

\footnotetext{
${ }^{16}$ Mencionado por Salas (2005) y tomado de los informes de gestión del proyecto. Departamento Administrativo de Acción Comunal Distrital.
}

de Ordenamiento Territorial (2000), en los cuales se reconocieron las zonas urbanas en consolidación como de desarrollo incompleto y se propuso aplicar allí el tratamiento de mejoramiento integral. Posteriormente, con un enfoque de desarrollo diferente, se incorporó al Plan de Desarrollo Distrital 2001-2004 en el objetivo de Justicia Social, en el programa de mejoramiento del barrio y la casa, manteniendo el esquema de responsabilidad compartida entre el sector público y la comunidad.

En el escenario de ordenamiento territorial, la escala zonal con el instrumento de la Unidad de Planeamiento Zonal-UPZ fue definitivo para el programa de mejoramiento de barrios. En 27 de las 117 UPZ urbanas de urbanización incompleta, con un área aproximada de 10.040 ha. urbanas se buscó aplicar el tratamiento de mejoramiento integral y en su interior se identificaron condiciones particulares con potencial particular de transformación que se denominaron sectores de modalidad reestructurante para intervenir prioritariamente con proyectos específicos que mejoraran la accesibilidad, los equipamientos y el espacio público $^{17}$. Como instrumento de planificación, pero también como espacio de concertación de la gestión para poner en marcha los proyectos, se pretendió orientar las acciones de inversión y precisar las demandas y prioridades del ordenamiento general de la ciudad, facilitando la participación de la comunidad y fortaleciendo su sentido de pertenencia a la ciudad.

Esta sinergia entre escenarios de decisión colectiva y actuaciones territoriales de escala zonal, permitió en los primeros años del programa conformar organizaciones cívicas de segundo nivel que se concretaron en los denominados "núcleos de participación zonal" en los cuales se convocaban representantes de las distintas organizacio-

\footnotetext{
${ }^{17}$ POT, Decreto 190 de 2004. Artículo 360 - Clases de tratamientos urbanísticos. Subcapítulo 5 - Artículo 385 y 386.
} 
nes sociales de base para formar parte de las mesas temáticas según las características de cada zona. Se constituyó para esa fase del programa un real proceso de pedagogía social y aprendizaje colectivo, generando espacios de participación ciudadana donde era altamente apreciable el valor político y ético al tratar las diferencias e intereses en forma clara y transpa- rente y el bienestar colectivo por encima del particular como valores de cultura ciudadana. Se desarrollaron también con apoyo desde la institucionalidad pública, instrumentos y metodologías que constituyeron verdaderas tecnologías de gestión para los procesos de mejoramiento y transformación de los entornos vecinales de los asentamientos en consolidación (Escallón, 2006).

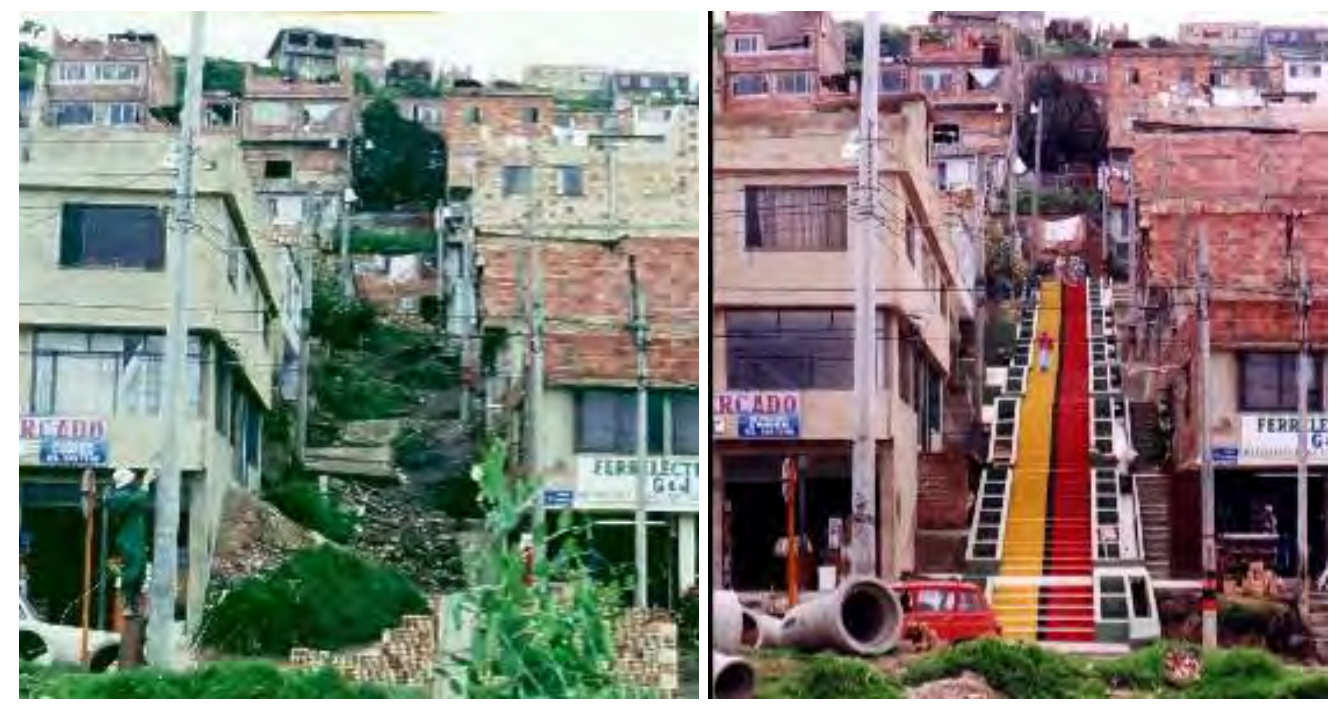

Figura 13. Obras con saldo Pedagógico. Barrio Horizontes. Fuente: Departamento administrativo de acción comunal, Bogotá.
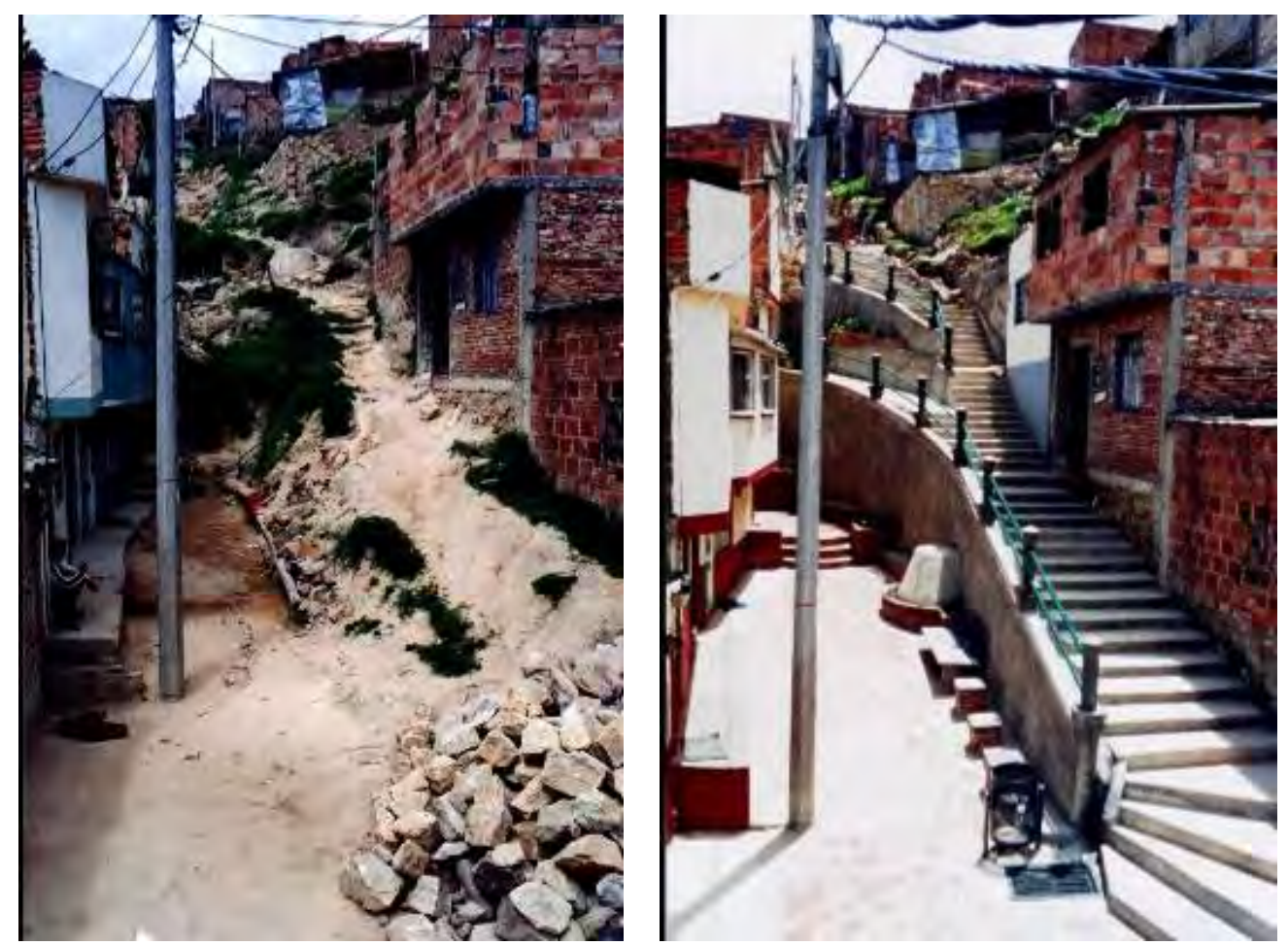

Figura 13. Obras con saldo Pedagógico. Barrio Ciudad Milagros. Fuente: Departamento administrativo de acción comunal, Bogotá. 


\section{Las lecciones no aprendidas o los retos de la gestión urbana}

La dinámica del programa de mejoramiento integral enfrenta en Bogotá en los últimos períodos administrativos, graves problemas de gestión. Parecería que los instrumentos del planeamiento y los instrumentos de gestión con los que se cuenta en la ciudad son los apropiados y se han adoptado medidas de ajuste institucional que también parecerían altamente pertinentes para este tipo de acciones, pero el programa en lugar de ajustarse y crecer en sus ejecuciones, languidece por ausencia casi total de actuación.

En los años recientes se reconoce desde la Secretaría de Distrital de Hábitat, en la Coordinación del programa de mejoramiento de barrios, avances notoriamente en el conocimiento del territorio, precisando los diagnósticos y elaborando detallados documentos para describir las actuaciones en las actualmente denominadas Áreas Prioritarias de Actuación (API). Son ejercicios juiciosos de planeamiento para 26 territorios en la ciudad, que no encuentra respuesta en los espacios de decisión en relación con los recursos para avanzar los proyectos (ver Figura 15).

Parecería que existe un desacuerdo sobre las estrategias de gestión que paraliza el escenario de actuación. Los discusiones internas en la administración van desde el cuestionamiento al programa de mejoramiento integral, pasando por la propuesta de revitalización en el actual Plan de Desarrollo 2012-2016 y más recientemente a la propuesta de Planes de mejoramiento urbanístico, contempladas en la revisión excepcional del Plan de ordenamiento territorial en discusión actualmente.

Parecería como si los aprendizajes de los programas y proyectos antes mencionados, en Obras con saldo Pedagógico y las primeras actuaciones del programa de mejoramiento integral, con espacios reales de coordinación y de ejecu- ción, tan solo unos pocos años atrás y con resultados muy exitosos, no pertenecieran a un mismo proceso urbano.

En relación con las operaciones de transformación, falta llenar un vacío. Las operaciones de reciclaje de barrios o transformaciones denominadas de renovación, aún no forman parte de la visión de futuro de la ciudad y no se encuentra aún un sentido colectivo para estas actuaciones. Las percepciones para los actores, residentes y propietarios de los sectores urbanos son muy disímiles: en relación con el mejoramiento de barrios, se percibe ausencia del Estado, poca claridad en la capacidad de actuación y bajas expectativas en relación con la inversión pública y en las operaciones de renovación, los residentes y propietarios se sienten afectados y perciben que las actuaciones de los agentes, tanto privados como públicos, se desarrollan apoyados en escenarios netamente inmobiliarios, casi siempre, en detrimento de sus intereses (Escallón, 2013).

En resumen, las estrategias están más enfocadas al resultado que al proceso y en ese sentido no se han identificado los aprendizajes y valorado las experiencias que puedan sacar adelante los proyectos. El esfuerzo se debería centrar en acercar y hacer coherentes las buenas intenciones de las propuestas técnicas con los buenos propósitos de los discursos políticos donde los ciudadanos perciban con claridad la evidencia de los cambios en beneficio de la calidad de vida tanto propia como de la colectividad.

La realidad es que la ciudad sigue su ritmo y los ciudadanos siguen haciendo su mejor esfuerzo para mejorar sus entornos, esperando que desde los escenarios de decisión se comprendan estos procesos y se apoyen debidamente en un real compromiso de revitalización como lo menciona en sus intenciones políticas la actual administración de la ciudad. 


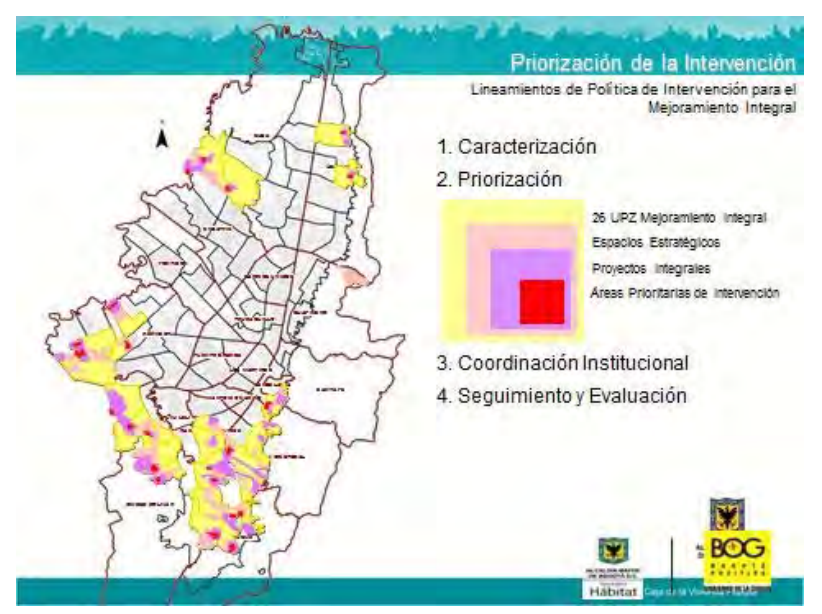

Figura 15. Programa de mejoramiento integral. Áreas prioritarias de intervención. Fuente: Secretaría de Hábitat. Dirección de mejoramiento integral de barrios, 2012.

\section{Referencias}

ALCALDÍA MAYOR DE BOGOTÁ. Plan de Desarrollo Económico, Social, Ambiental y de Obras Públicas para Bogotá D.C: 2012-2016 "Bogotá Humana". Acuerdo 489 de 2012 (12 de junio de 2012). Bogotá, 2012.

ALCALDÍA MAYOR DE BOGOTÁ. Decreto 190 de 2004 - Plan de Ordenamiento Territorial POT. Bogotá, 2004.

ALCALDÍA MAYOR DE BOGOTÁ. Plan de Ordenamiento Territorial POT. Documento Técnico de Soporte. Bogotá, 2000.

ALCALDÍA MAYOR DE BOGOTÁ. La planificación en Bogotá. Bogotá, 1964.

ARTEAGA, Isabel et al. La política de renovación urbana en Bogotá. Balance sobre los planes parciales de renovación formulados entre 20052010. Bogotá: Investigación sin publicar. Universidad de Los Andes. 2012.

ESCALLÓN, Clemencia. El proyecto obras con saldo pedagógico en Bogotá. Avances y reflexiones. Ciudades urgentes. Bogotá: Javegraf, 2006, p. 117-140.

ESCALLÓN, Clemencia. Gobernanza en procesos de regeneración urbana. Aproximaciones al caso de Bogotá. Bogotá: Tesis Maestría en Estudios Interdisciplinarios de Desarrollo. CIDER,
Universidad de los Andes, 2013.

MERLIN, Pierre; CHOAY, Françoise. Dictionnaire de l'urbanisme et de l'amenagement. Paris: Presses Universitaires de France, 2000.

MOZAS, Javier. Los procesos de Regeneración, Reutilización y Reciclaje como expropiación. Revista A+T. Reclaim. Remediate, Reuse, Recicle. No. 39-40. Barcelona, 2012.

ROBERTS, Peter; SYKES, Hugh. Urban Regeneration: A handbook. London: British Urban Regeneration Association, SAGE Publications, 2000.

SALAZAR, José; CORTÉS, Rodrigo. Planificación, renovación y manejo de la ciudad edificada. Bogotá: Informe de investigación sin publicar, realizado para el Banco Central Hipotecario y la Misión Bogotá Siglo XXI, 1992.

SALAS, Julián. Mejora de barrios precarios en latinoamérica. Elementos de teoría y práctica. Bogotá: Editorial Escala, 2005.

SALDARRIAGA, Alberto. La ciudad informal en Colombia: ¿Problema o solución? en GORDILHO-SOUZA, A.; PIÑÓN, J.L. (Ed.) La recomposición de la ciudad informal. Valencia, España: Centro Internacional de Ciudad Informal, Universidad Politécnica de Valencia, 2001.

SCHUMACHER, E. F. Small Is Beautiful: Economics as if People Mattered. London: Blond \& Briggs, 1973.

SECCHI, Bernardo. Le condizione sono cambiante. Revista Casabella, No 498-499, 1984.

SOLÁ-MORALES, Manuel. Territoris sense model. Revista Papers, No. 33. Regió Metropolitana de Barcelona, 1997.

\section{Cita del artículo}

ARTEAGA ARREDONDO, I., ESCALLÓN

GARTNER, C. Entre la renovación y el reciclaje de tejidos urbanos consolidados. El debate actual en Bogotá. Hábitat y Sociedad, 2012, no 5, p. 57-75. $<$ <ww.habitatysociedad.us.es>.

http://dx.doi.org/10.12795/HabitatySociedad.2012.i5.05 